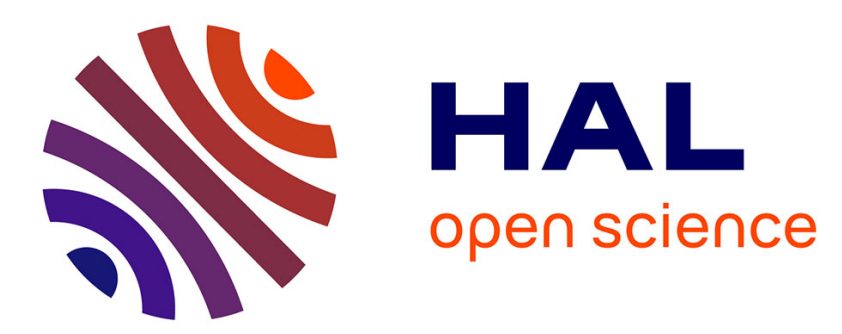

\title{
Influence of ball milling on quasicrystal formation in melt-spun Zr-based glassy ribbons
}

Sergio Scudino, J Eckert, Hergen Breitzke, Klaus Lüders, Ludwig Schultz

\section{To cite this version:}

Sergio Scudino, J Eckert, Hergen Breitzke, Klaus Lüders, Ludwig Schultz. Influence of ball milling on quasicrystal formation in melt-spun Zr-based glassy ribbons. Philosophical Magazine, 2005, 86 (03-05), pp.367-371. 10.1080/14786430500228499 . hal-00513557

\section{HAL Id: hal-00513557 https://hal.science/hal-00513557}

Submitted on 1 Sep 2010

HAL is a multi-disciplinary open access archive for the deposit and dissemination of scientific research documents, whether they are published or not. The documents may come from teaching and research institutions in France or abroad, or from public or private research centers.
L'archive ouverte pluridisciplinaire HAL, est destinée au dépôt et à la diffusion de documents scientifiques de niveau recherche, publiés ou non, émanant des établissements d'enseignement et de recherche français ou étrangers, des laboratoires publics ou privés. 


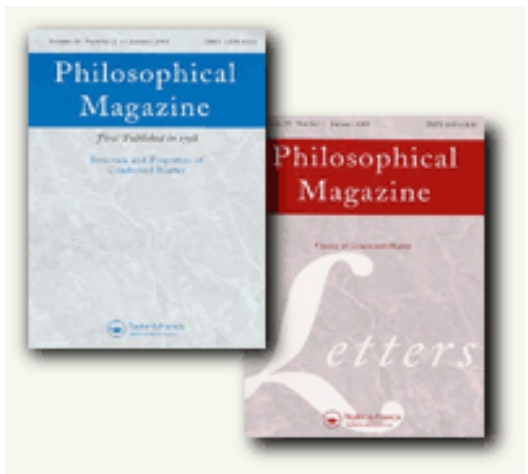

\section{Influence of ball milling on quasicrystal formation in melt- spun Zr-based glassy ribbons}

\begin{tabular}{|r|l|}
\hline Journal: & Philosophical Magazine \& Philosophical Magazine Letters \\
\hline Manuscript ID: & TPHM-05-Apr-0123 \\
\hline Journal Selection: & Philosophical Magazine \\
\hline Author: & 28-Apr-2005 \\
\hline Complete List of Authors: & $\begin{array}{l}\text { Scudino, Sergio; IFW Dresden, Institut für Metallische Werkstoffe } \\
\text { Eckert, J; Technische Universität Darmstadt, FB 11 Material- und } \\
\text { Geowissenschaften } \\
\text { Breitzke, Hergen; Freie Universität Berlin, Fachbereich Physik } \\
\text { Lüders, Klaus; Freie Universität Berlin, Fachbereich Physik } \\
\text { Schultz, Ludwig; IFW Dresden, Institut für Metallische Werkstoffe }\end{array}$ \\
\hline Keywords: & metallic glasses, quasicrystals, ball-milling \\
\hline Keywords (user supplied): & \multicolumn{2}{|l}{} \\
\hline
\end{tabular}

\section{S) ScholaroNE \\ Manuscript Central}


Influence of ball milling on quasicrystal formation in melt-spun Zr-based glassy ribbons

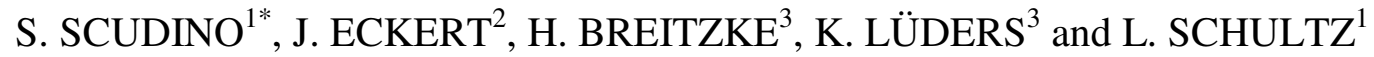 \\ ${ }^{1}$ IFW Dresden, Institut für Metallische Werkstoffe, Postfach 270016, D-01171 Dresden, Germany \\ ${ }^{2}$ FG Physikalische Metallkunde, FB 11 Material- und Geowissenschaften, Technische Universität \\ Darmstadt, Petersenstraße 23, D-64287 Darmstadt, Germany \\ ${ }^{3}$ Fachbereich Physik, Freie Universität Berlin, Arnimallee 14, D-14195 Berlin, Germany.
}

\begin{abstract}
The effect of mechanical deformation on the formation of quasicrystals in $\mathrm{Zr}_{57} \mathrm{Ti}_{8} \mathrm{Nb}_{2.5} \mathrm{Cu}_{13.9} \mathrm{Ni}_{11.1} \mathrm{Al}_{7.5}$ glassy ribbons has been investigated. The mechanical treatment drastically affects the crystallization behavior and, in particular, suppresses primary quasicrystal formation. However, quasicrystals can be formed by the addition of the appropriate amount of zirconium. This indicates that if a particular short-range (e.g., icosahedral) is required for quasicrystal formation and if this short-range order is altered during milling, it can be restored by appropriately adjusting the chemical composition.
\end{abstract}

Keywords: glasses, quasicrystals, ball milling.

* Email: s.scudino@ifw-dresden.de 


\section{Introduction}

More than fifty years ago Frank [1] proposed that metallic liquids might be characterized by an icosahedral short-range order (SRO). Another state of matter that is believed to possess icosahedral SRO is the glassy state $[2,3]$. The degree of icosahedral SRO is predicted to increase with increasing undercooling of the liquid [4]. Since metallic glasses may be considered as deeply undercooled liquids, it has been proposed that in glassy alloys the SRO characterizing the liquid may be quenched-in during vitrification [5]. This may subsequently promote the formation of quasicrystals (QC) upon crystallization of the glass. Recently, this assumption has been corroborated by Saida et al. [6] who observed a change of the primary devitrification product from quasicrystalline to big cube phase upon ball milling. The authors proposed that the distortion due to the mechanical treatment induces changes in the local icosahedral structure in the glassy state and, therefore, leads to a different crystallization behavior. However, QC formation directly during mechanical alloying has been reported for Al-based alloys [7] and recently in solid-state synthesized Zr-based glassy powders, which undergo QC formation upon crystallization [8,9]. This indicates that the SRO responsible for QC formation can be achieved also by solid-state reaction with no need of quenching from the melt.

In this work, this aspect has been further investigated by studying the influence of mechanical deformation on QC formation for melt-spun $\mathrm{Zr}_{57} \mathrm{Ti}_{8} \mathrm{Nb}_{2.5} \mathrm{Cu}_{13.9} \mathrm{Ni}_{11.1} \mathrm{Al}_{7.5}$ glassy ribbons. The ribbons were subjected to ball milling up to the suppression of QC formation. The results demonstrate that the suppression of QC formation can be reversed by an appropriate variation of the chemical composition.

\section{Experimental}

Ribbons with a cross section of about $0.05 \times 3 \mathrm{~mm}^{2}$ were prepared in a single-roller Bühler melt spinner at a wheel velocity of $14.3 \mathrm{~m} \mathrm{~s}^{-1}$ from pre-alloyed arc-melted ingots with 
nominal composition $\mathrm{Zr}_{57} \mathrm{Ti}_{8} \mathrm{Nb}_{2.5} \mathrm{Cu}_{13.9} \mathrm{Ni}_{11.1} \mathrm{Al}_{7.5}$. Milling experiments starting from the melt-spun $\mathrm{Zr}_{57} \mathrm{Ti}_{8} \mathrm{Nb}_{2.5} \mathrm{Cu}_{13.9} \mathrm{Ni}_{11.1} \mathrm{Al}_{7.5}$ ribbons were performed using a Retsch PM400 planetary ball mill and hardened steel balls and vials. All sample handling was carried out in a glove box under purified argon atmosphere (less than 1 ppm $\mathrm{O}_{2}$ and $\mathrm{H}_{2} \mathrm{O}$ ). The ribbons were milled for $100 \mathrm{~h}$ at a ball-to-powder mass ratio of 13:1 using a milling speed of $150 \mathrm{rpm}$. The oxygen content, evaluated by carrier gas hot extraction, was found to be about 0.18 wt.\%. The microstructure was characterized by X-ray diffraction (XRD) (Co $K_{\alpha}$ radiation) and by transmission electron microscopy (TEM). The thermal stability of the samples was investigated by differential scanning calorimetry (DSC) at $40 \mathrm{~K} \mathrm{~min}^{-1}$ heating rate under a continuous flow of purified argon.

\section{Results and discussion}

The characterization of the melt-spun $\mathrm{Zr}_{57} \mathrm{Ti}_{8} \mathrm{Nb}_{2.5} \mathrm{Cu}_{13.9} \mathrm{Ni}_{11.1} \mathrm{Al}_{7.5}$ ribbon has been reported elsewhere $[10,11]$. However, some key features have to be quoted here. The as-spun ribbon is amorphous and is characterized by a multi-step crystallization behavior in which the primary phase formed is a metastable icosahedral quasicrystalline phase of nanometer-scale dimensions $[10,11]$.

Fig. 1(a) shows the XRD pattern of $\mathrm{Zr}_{57} \mathrm{Ti}_{8} \mathrm{Nb}_{2.5} \mathrm{Cu}_{13.9} \mathrm{Ni}_{11.1} \mathrm{Al}_{7.5}$ ribbons after milling for $100 \mathrm{~h}$. The mechanical deformation does not induce crystallization, as shown by the XRD pattern, which displays the diffuse diffraction maxima typical of amorphous materials. However, the DSC scan (40 $\mathrm{K} \mathrm{min}^{-1}$ ) of the ball-milled (BM) ribbon (Fig. 2) shows some differences with respect to the as-spun $\mathrm{Zr}_{57} \mathrm{Ti}_{8} \mathrm{Nb}_{2.5} \mathrm{Cu}_{13.9} \mathrm{Ni}_{11.1} \mathrm{Al}_{7.5}$ ribbon [11]. The exothermic DSC peaks are broader and are characterized by a convergent shift compared with the parent as-spun material [11], which gives rise to a partial overlapping of the exothermic signals. The values of $T_{g}$ and $T_{x l}$ are higher (646 and $703 \mathrm{~K}$, respectively) than for the as-spun ribbon (637 and $682 \mathrm{~K}$, respectively), indicating that the mechanical treatment enhances the 
thermal stability against crystallization. Finally, the crystallization enthalpy related to the first exothermic DSC peak of the ribbon milled for $100 \mathrm{~h}\left(13.3 \mathrm{Jg}^{-1}\right)$ is lower compared to the asspun ribbon [11], suggesting a decrease of the crystallized volume fraction.

The XRD pattern for the BM ribbon heated up to completion of the first crystallization event is presented in Fig. 1(b). The diffraction peaks belonging to the QC phase characterizing the XRD pattern of the as-spun ribbon [11] are no longer visible. Instead, the XRD pattern shows extremely broad diffraction peaks, corresponding to an unidentified phase of nanoscale dimensions, superimposed on the amorphous haloes.

It has been reported that the lack of QC formation in mechanically alloyed (MA) $\mathrm{Zr}_{62} \mathrm{Ti}_{7.07} \mathrm{Nb}_{2.21} \mathrm{Cu}_{12.28} \mathrm{Ni}_{9.81} \mathrm{Al}_{6.63}$ glassy powders is due to preferential oxidation of $\mathrm{Zr}$ during milling, which shifts the composition of the glassy phase outside of the range suitable for QC formation [9]. If an adequate amount of elemental $\mathrm{Zr}$ is added, the oxidation drawback can be bypassed and the MA glassy powders undergo QC formation upon crystallization [9]. Consequently, oxygen contamination might also be the reason for the suppression of QC formation in the BM ribbon.

In order to test this hypothesis, 5 at.\% elemental $\mathrm{Zr}$ was added to the $\mathrm{BM}$ ribbon. Subsequently, the material was milled for $100 \mathrm{~h}$ at $150 \mathrm{rpm}$. The addition of elemental $\mathrm{Zr}$ to the $\mathrm{BM}$ ribbon considerably alters the thermal stability as well as the microstructure evolution of the material. The DSC scan of the $\mathrm{BM}$ ribbon $+\mathrm{Zr}$ is shown in Fig. 2. The partial overlapping of the exothermic DSC peaks characterizing the BM ribbon is no longer observable and the crystallization events are clearly resolved. The values of $T_{\mathrm{g}}$ and $T_{\mathrm{x} 1}$ are found to be decreased (612 and $660 \mathrm{~K}$, respectively) with respect to the parent materials and the value of the crystallization enthalpy $\left(26.4 \mathrm{Jg}^{-1}\right)$ is similar to that of the as-spun ribbon [11], suggesting a similar transformed volume fraction. When the $\mathrm{BM}$ ribbon $+\mathrm{Zr}$ is heated above the first crystallization event the XRD pattern [Fig. 1(d)] reveals the formation of a phase that, 
according to the scheme of Bancel et al. [12], can be indexed as an icosahedral quasicrystalline phase with quasilattice constant $a_{q}=0.480 \mathrm{~nm}$.

The icosahedral structure of the first crystallization product was corroborated by TEM investigations. Fig. 3 shows a bright-field TEM image of the BM ribbon $+\mathrm{Zr}$ after heating up to the completion of the first exothermic DSC peak. It reveals a homogeneous distribution of particles with a size on the order of $10-20 \mathrm{~nm}$. The electron diffraction pattern taken from the precipitated particles is presented in the inset in Fig. 3. The pattern clearly exhibits five-fold rotational symmetry. The distances between the diffraction spots along the radial directions are related each to other by $\tau=(1+\sqrt{5}) / 2$, the golden mean. In addition, the angles between the spots are $2 \pi / 10=36^{\circ}$. This confirms the results from XRD, corroborating that the particles precipitated in the first crystallization event have an icosahedral structure.

\section{Conclusions}

Mechanical treatment suppresses the formation of quasicrystals in melt-spun $\mathrm{Zr}_{57} \mathrm{Ti}_{8} \mathrm{Nb}_{2.5} \mathrm{Cu}_{13.9} \mathrm{Ni}_{11.1} \mathrm{Al}_{7.5}$ glassy ribbons. The suppression of $\mathrm{QC}$ formation due to the mechanical deformation can be reversed by adequately adjusting the chemical composition. These findings indicate that quasicrystal formation in the ball-milled ribbon is crucially linked to the chemical composition rather than to the question whether there is a special quenched-in short-range order.

\section{Acknowledgements}

The authors would like to thank M. Frey and H. Schulze for technical assistance, J. Acker and W. Gruner for chemical analysis and C. Mickel for help with the TEM investigations. This work was supported by the German Science Foundation under grants Ec 111/10-1,2 and Lu 217/17-1,2. 


\section{References}

[1] F.C. Frank, Proc. R. Soc. London A 21543 (1952).

[2] S. Sachdev and D. R. Nelson, Phys. Rev. B 324592 (1985).

[3] H. Jònsson and H. Andersen, Phys. Rev. Lett. 602295 (1988).

[4] P.J. Steinhardt, D.R. Nelson, and M. Ronchetti, Phys. Rev. B 28784 (1983).

[5] Y. Shen, S.J. Poon, and G. Shiflet, Phys. Rev. B 343516 (1986).

[6] J. Saida, M. S. El-Eskandarany, and A. Inoue, Scripta Mater. 481397 (2003).

[7] J. Eckert, L. Schultz, and K. Urban, Appl. Phys. Lett. 55117 (1989).

[8] S. Scudino, J. Eckert, U. Kühn, and L. Schultz, Appl. Phys. Lett. 832345 (2003).

[9] S. Scudino, C. Mickel, L. Schultz, J. Eckert, X. Y. Yang, and D. J. Sordelet, Appl. Phys. Lett. 854349 (2004).

[10] U. Kühn, J. Eckert, and L. Schultz, Appl. Phys. Lett. 773176 (2000).

[11] S. Scudino, U. Kühn, L. Schultz, D. Nagahama, K. Hono, and J. Eckert, J. Appl. Phys. 95 3397 (2004).

[12] P.A. Bancel, P.A. Heiney, P.W. Stephens, A.I. Goldman, and P.M. Horn, Phys. Rev. Lett. 542422 (1985). 


\section{Figure captions}

Figure 1. XRD patterns (Co $K_{\alpha}$ radiation) for: (a) as-milled $\mathrm{Zr}_{57} \mathrm{Ti}_{8} \mathrm{Nb}_{2.5} \mathrm{Cu}_{13.9} \mathrm{Ni}_{11.1} \mathrm{Al}_{7.5}$ glassy ribbon milled for $100 \mathrm{~h}$, (b) $\mathrm{Zr}_{57} \mathrm{Ti}_{8} \mathrm{Nb}_{2.5} \mathrm{Cu}_{13.9} \mathrm{Ni}_{11.1} \mathrm{Al}_{7.5}$ ribbon milled for $100 \mathrm{~h}$ heated up to the completion of the first exothermic DSC event, (c) as-prepared $\mathrm{Zr}_{57} \mathrm{Ti}_{8} \mathrm{Nb}_{2.5} \mathrm{Cu}_{13.9} \mathrm{Ni}_{11.1} \mathrm{Al}_{7.5}$ ribbon milled for $100 \mathrm{~h}+5$ at.\% $\mathrm{Zr}$ and (d) $\mathrm{Zr}_{57} \mathrm{Ti}_{8} \mathrm{Nb}_{2.5} \mathrm{Cu}_{13.9} \mathrm{Ni}_{11.1} \mathrm{Al}_{7.5}$ ribbon milled for $100 \mathrm{~h}+5$ at.\% $\mathrm{Zr}$ heated to completion of the first exothermic DSC event.

Figure 2. DSC traces (heating rate $40 \mathrm{~K} \mathrm{~min}^{-1}$ ) for: $\mathrm{Zr}_{57} \mathrm{Ti}_{8} \mathrm{Nb}_{2.5} \mathrm{Cu}_{13.9} \mathrm{Ni}_{11.1} \mathrm{Al}_{7.5}$ glassy ribbon milled for $100 \mathrm{~h}$ and $\mathrm{Zr}_{57} \mathrm{Ti}_{8} \mathrm{Nb}_{2.5} \mathrm{Cu}_{13.9} \mathrm{Ni}_{11.1} \mathrm{Al}_{7.5}$ ribbon milled for $100 \mathrm{~h}+5$ at.\% $\mathrm{Zr}$.

Figure 3. TEM image and corresponding diffraction pattern of the $\mathrm{Zr}_{57} \mathrm{Ti}_{8} \mathrm{Nb}_{2.5} \mathrm{Cu}_{13.9} \mathrm{Ni}_{11.1} \mathrm{Al}_{7.5}$ ribbon milled for $100 \mathrm{~h}+\mathrm{Zr}$ heated to completion of the first exothermic DSC event. 


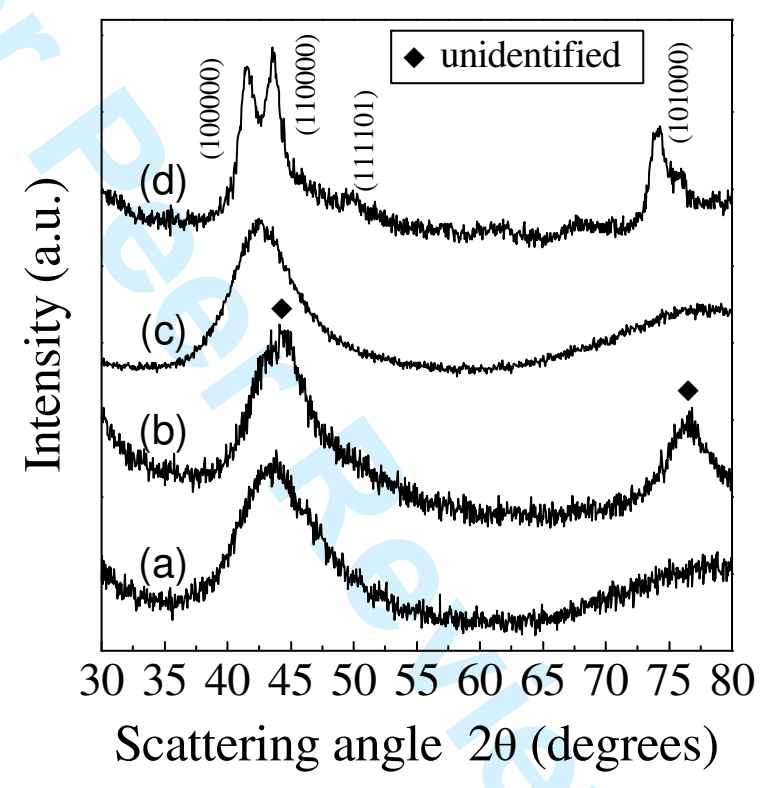

Figure 1 


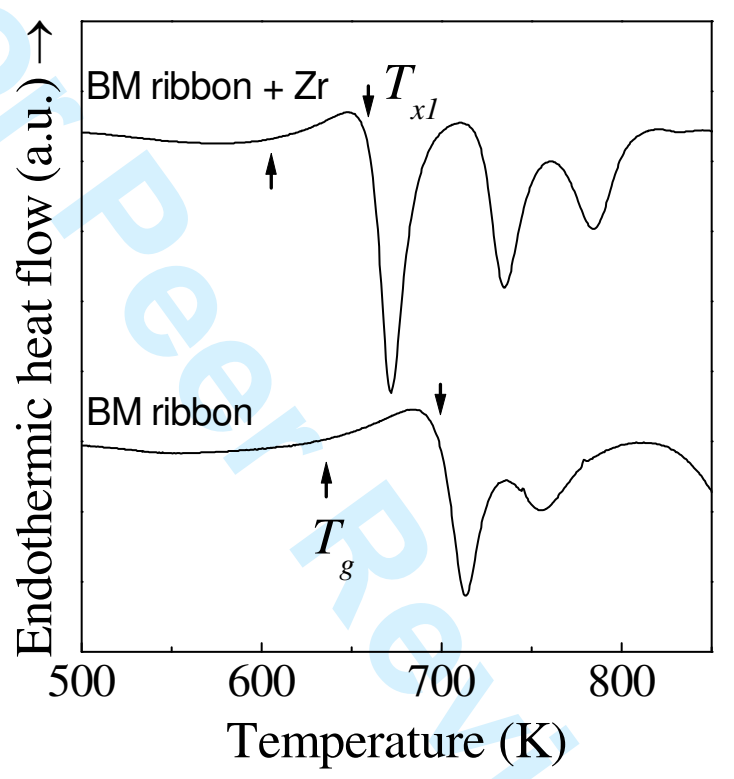

Figure 2 


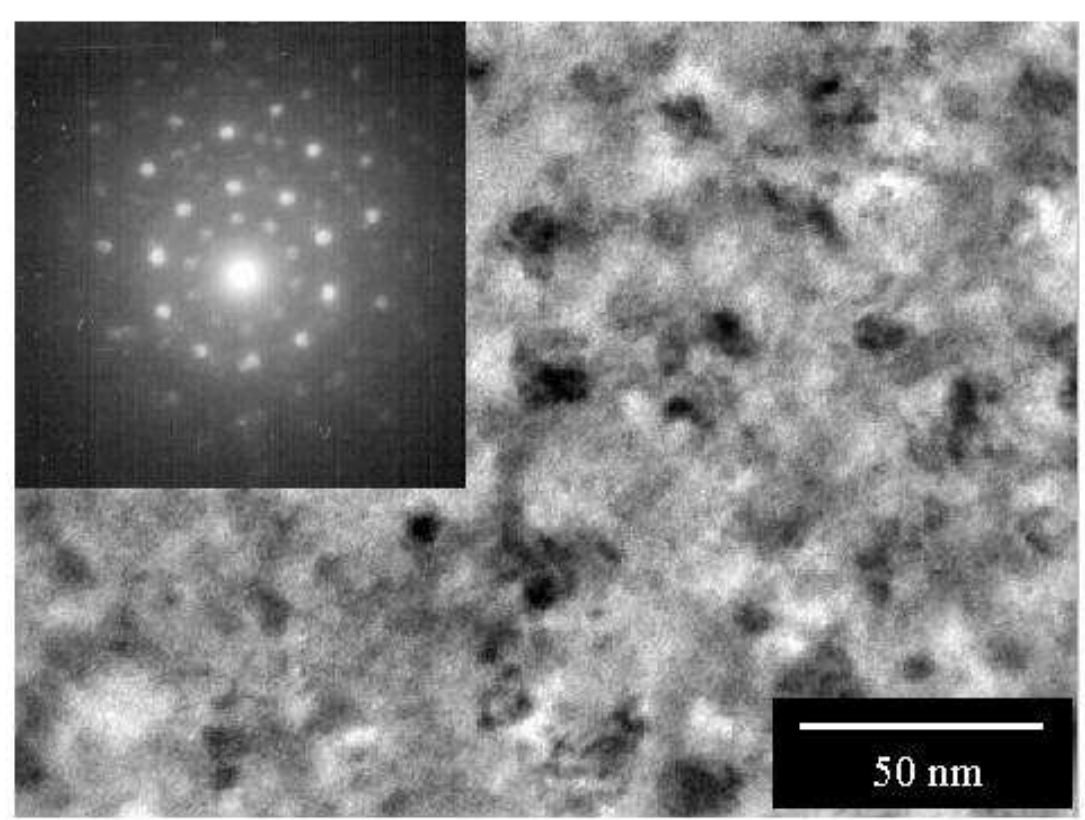

Figure 3 